\title{
Polydeoxyribonucleotide Improves Peripheral Tissue Oxygenation and Accelerates Angiogenesis in Diabetic Foot Ulcers
}

\author{
Seoyoung Kim ${ }^{1}$, Junhyung $\mathrm{Kim}^{1}$, Jaehoon $\mathrm{Choi}^{1}$, Woonhyeok Jeong ${ }^{1}$, Sunyoung Kwon ${ }^{2}$ \\ Departments of ${ }^{1}$ Plastic and Reconstructive Surgery and ${ }^{2}$ Pathology, Keimyung University Dongsan Medical Center, Keimyung University \\ School of Medicine, Daegu, Korea
}

Background Polydeoxyribonucleotide (PDRN) is known to have anti-inflammatory and angiogenic effects and to accelerate wound healing. The aim of this study was to investigate whether PDRN could improve peripheral tissue oxygenation and angiogenesis in diabetic foot ulcers.

Methods This was a prospective randomized controlled clinical trial. Twenty patients with a non-healing diabetic foot ulcer were randomly distributed into a control group $(n=10)$ and a PDRN group $(\mathrm{n}=10)$. Initial surgical debridement and secondary surgical procedures such as a split-thickness skin graft, primary closure, or local flap were performed. Between the initial surgical debridement and secondary surgical procedures, $0.9 \%$ normal saline $(3 \mathrm{~mL})$ or PDRN was injected for 2 weeks by the intramuscular ( 1 ampule, $3 \mathrm{~mL}, 5.625 \mathrm{mg}, 5$ days per week) and perilesional routes ( 1 ampule, $3 \mathrm{~mL}, 5.625 \mathrm{mg}, 2$ days per week). Transcutaneous oxygen tension $\left(\mathrm{TcPO}_{2}\right)$ was evaluated using the Periflux System 5000 with $\mathrm{TcPO}_{2} / \mathrm{CO}_{2}$ unit 5040 before the injections and on days 1, 3, 7, 14, and 28 after the start of the injections. A pathologic review (hematoxylin and eosin stain) of the debrided specimens was conducted by a pathologist, and vessel density (average number of vessels per visual field) was calculated.

Results Compared with the control group, the PDRN-treated group showed improvements in peripheral tissue oxygenation on day $7(P<0.01)$, day $14(P<0.001)$, and day $28(P<0.001)$. The pathologic review of the specimens from the PDRN group showed increased angiogenesis and improved inflammation compared with the control group. No statistically significant difference was found between the control group and the PDRN group in terms of vessel density $(P=0.094)$. Complete healing was achieved in every patient.

Conclusions In this study, PDRN improved peripheral tissue oxygenation. Moreover, PDRN is thought to be effective in improving inflammation and angiogenesis in diabetic foot ulcers.

Keywords Polydeoxyribonucleotides / Foot ulcer / Blood Gas Monitoring, transcutaneous / Angiogenesis modulating agents
Correspondence: Junhyung Kim Department of Plastic and Reconstructive Surgery, Keimyung University Dongsan Medical Center, Keimyung University School of Medicine, 56 Dalseong-ro, Jung-gu, Daegu 41931, Korea

Tel: $+82-53-250-7635$

Fax: +82-53-255-0632

E-mail:med69@dsmc.or.kr

Received: 27 Apr 2017 • Revised: 7 Sep 2017 • Accepted: 10 Oct 2017

pISSN: 2234-6163 • elSSN: 2234-6171 • https://doi.org/10.5999/aps.2017.00801 • Arch Plast Surg 2017;44:482-489

This article was presented at the 74th Congress of the Korean Society of Plastic and Reconstructive Surgeons on November 17-20, 2016 in Seoul, Korea.

\section{INTRODUCTION}

Diabetic foot ulcers are a common condition, characterized by chronic ulceration with vascular complications that impede the normal wound healing process [1]. Diabetic foot ulcers are the most common foot injuries leading to foot pain and poor quali- 
ty of life due to lower extremity amputation. In diabetics, the combined effects of peripheral neuropathy, peripheral vascular disease, and infection aggravate ulceration, potentially leading to amputation. Peripheral arterial insufficiency with neuropathy has associated with a 10-fold increase in the risk of ulceration progressing to infection, gangrene, and amputation [2]. Consequently, diabetic foot ulcers are one of the most challenging conditions for plastic surgeons to treat.

Polydeoxyribonucleotide (PDRN) is obtained from sperm of trout by an extraction process in which purification and hightemperature sterilization procedures are performed to obtain an $>95 \%$ pure active product. This compound is low-molecularweight DNA containing a mixture of deoxyribonucleotide polymers with chain lengths ranging between 50 and 2000 base pairs. In vitro, PDRN has been shown to enhance the growth rate of human fibroblasts and osteoblasts in primary cultures at therapeutic concentrations [3,4]. In vivo, PDRN has been shown to enhance wound healing in an experimental model of thermal injury, in diabetic mice, and in ischemic skin flaps [5-7]. In addition, PDRN enhanced angiogenesis and neovascularization in a model of peripheral artery occlusive disease [8]. The cell proliferation effect appears to be mediated by the activation of purinergic adenosine $\mathrm{A}_{2 \mathrm{~A}}$ receptor [4].

The use of PDRN in reconstructive surgery is steadily becoming more popular, as evidence of the regenerative and reparative effects of PDRN becomes better known. The aim of this study was to investigate whether PDRN could improve peripheral tissue oxygenation and angiogenesis in diabetic foot ulcers.

\section{METHODS}

This was prospective randomized controlled clinical trial. All patients provided written informed consent before being enrolled. The experimental protocol was approved by the Institutional Review Board of Keimyung University in Korea (DSMC02-011).

Patients who met the inclusion criteria were randomly chosen to receive a placebo $(n=10)$ or PDRN $(n=10)$. To estimate the number of patients that would be needed, we adapted the protocol of a publication that was similar to our experimental protocol [9]. Based on the results of that study, we calculated the sample size for a power of $80 \%$ and a significance level of 0.05 , supposing that the study would be effective. Based on this calculation, 10 patients were included in each group.

\section{Inclusion and exclusion criteria}

The inclusion criterion was type 2 diabetes with the presence of a Wagner grade 1 to 4 diabetic foot ulcer. Patients with transcu- taneous oxygen tension $\left(\mathrm{TcPO}_{2}\right)$ greater than $40 \mathrm{~mm} \mathrm{Hg}$ and an ankle-brachial blood pressure index greater than 0.8 were included.

The exclusion criteria were a history of allergies or drug shock, uncontrolled diabetic mellitus (hemoglobin Alc > 8\%), diabetic ketoacidosis, severe liver disease (i.e., jaundice), renal failure (serum creatinine $>2 \mathrm{mg} / \mathrm{dL}$ ), a history of drug or alcohol abuse, sensitivity to PDRN, and the concurrent use of corticosteroids or immunosuppressive drugs.

\section{Experimental protocol}

Initial surgical debridement of the necrotic tissue was performed under spinal or local anesthesia. After the initial surgical debridement, PDRN was administered for 2 weeks by daily intramuscular administration for 5 days per week ( 1 ampule, 3 $\mathrm{mL}, 5.625 \mathrm{mg}$ ) and through the perilesional route for 2 days per week ( 1 ampule, $3 \mathrm{~mL}, 5.625 \mathrm{mg}$ ). The PDRN vials (Rejuvenex; Pharma Research Product, Gangneung, Korea) contained $5.625 \mathrm{mg}$ of the substance in $3 \mathrm{~mL}$ as the active ingredient. Perilesional administration was performed by an experienced physician in the hospital setting using a $30-G$ needle insulin syringe. Intramuscular injections of PDRN were performed on the buttock (gluteus maximus muscle) on the side of the wound. Perilesional injections of PDRN were made around the debrided wound in the intradermal layer. If a wound was too small for $3 \mathrm{~mL}$ of PDRN to be injected, the remaining PDRN was injected extensively around the wound to prevent complications of injection, such as vessel compromise. The patients were evaluated before the injections, and then on days 1, 3, 7, and 14 of the injections. After 2 weeks of PDRN administration, surgical procedures (debridement and primary closure, debridement and a local flap, or debridement and a split-thickness skin graft) were performed to cover the ulcerative lesions. Finally, 2 weeks after the coverage operation, the patients were evaluated. The control group was evaluated after the administration of $3 \mathrm{~mL}$ of $0.9 \%$ normal saline (Fig. 1) [10,11].

\section{Transcutaneous oxygen tension measurements}

$\mathrm{TcPO}_{2}(\mathrm{~mm} \mathrm{Hg})$ was recorded using a Periflux System 5000 with the $\mathrm{TcPO}_{2} / \mathrm{CO}_{2}$ unit 5040 (Fig. 2). This study was performed in a room where the temperature was maintained at 22 $24^{\circ} \mathrm{C}$. The sensor of $\mathrm{TcPO}_{2}$ contacts the patient's skin with adhesive rings and contact liquid. The transducer of the probe was heated to $44^{\circ} \mathrm{C}$. The transcutaneous tissue oxygen level was measured after it reached a steady plateau state, on the same angiosome just proximal to the ulcerative lesion (Fig. 3). Transcutaneous tissue oxygen levels were evaluated before the injections and on days 1,3, 7, 14, and 28. 


\section{Fig. 1. Treatment protocol of the study}

PDRN, polydeoxyribonucleotide; IM, intramuscular; $\mathrm{TCPO}_{2}$, transcutaneous oxygen tension.

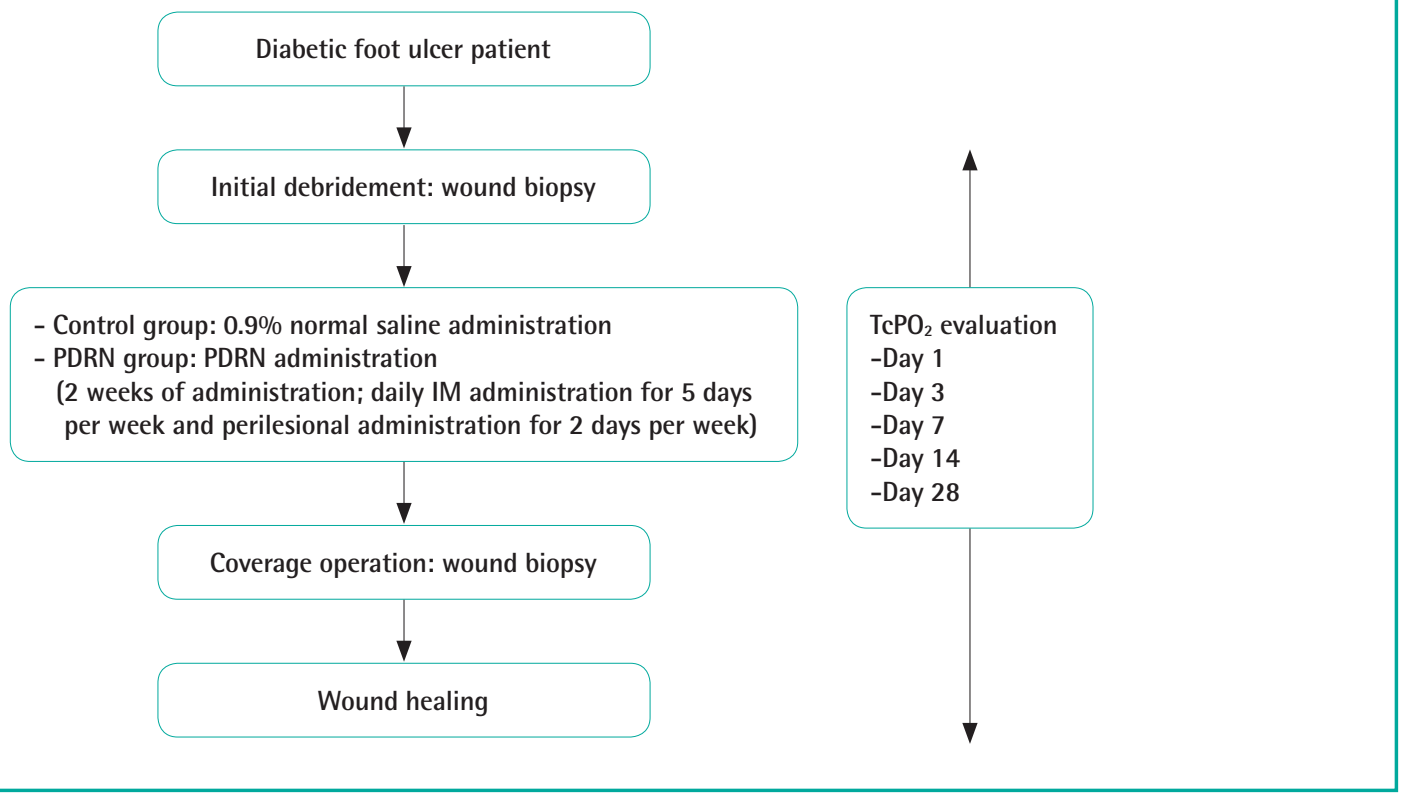

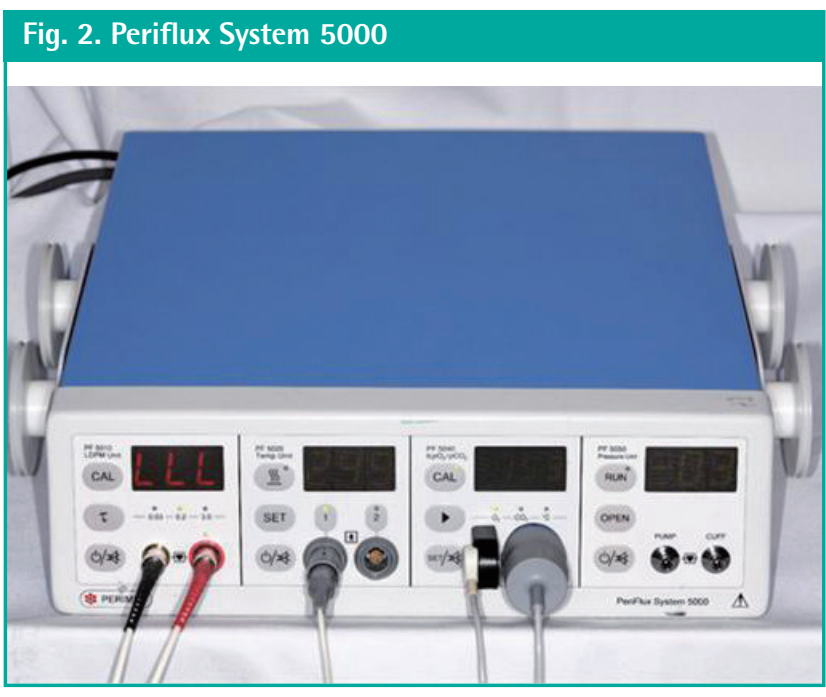

\section{Histologic analysis}

Surgical wound debridement was performed before PDRN administration and after 2 weeks of PDRN administration. A piece of full-thickness tissue surrounding the ulcerative lesion measuring $0.3 \mathrm{~cm} \times 0.5 \mathrm{~cm}$ was harvested, including samples from both normal tissue and the ulcerative tissue. All tissue specimens were fixed in $10 \%$ neutral-buffed formalin for at least 24 hours at room temperature, embedded in paraffin, and sectioned in 4- $\mu \mathrm{m}$ slices. Each section was stained with hematoxylin and eosin according to a standard protocol. The slide sections were evaluated by a single pathologist blinded to the treatment at $\times 10, \times 40, \times 200$, and $\times 400$ magnification. To evaluate vessel
Fig. 3. Measurements of transcutaneous tissue oxygen levels

Transcutaneous tissue oxygen levels were measured on the same angiosome, just proximal to the ulcerative lesion. (A) Control group, day 7. (B) PDRN-treated group, day 28. PDRN, polydeoxyribonucleotide.
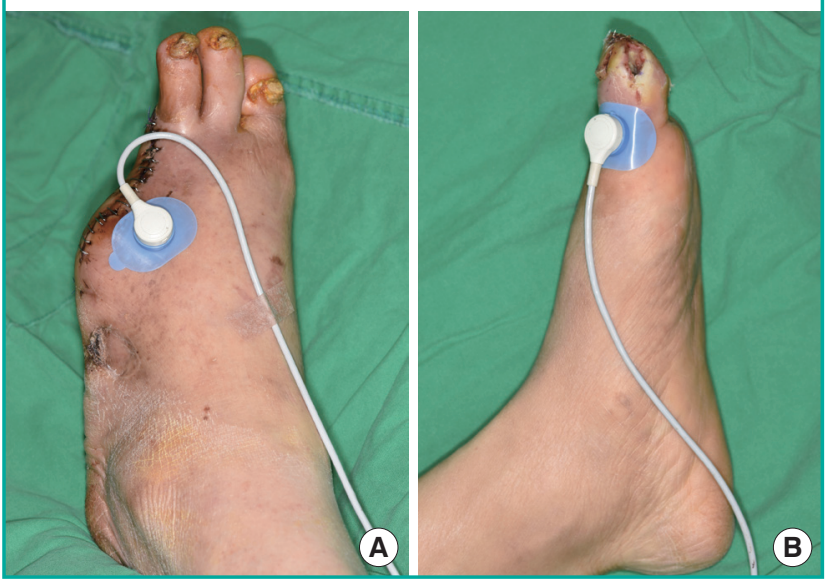

density, sections were scanned at $\times 40$ magnification, and the areas with the highest concentration of vessels were selected. In the selected areas, the number of blood vessels was counted in 4 different $\times 400$ magnification fields. The results were expressed as the average number of vessels per visual field $[12,13]$.

\section{Statistical analysis}

Differences between the PDRN-treated group and the control group were tested using repeated-measures analysis of variance. 


\section{Fig. 4. Flow chart of the study}

PDRN, polydeoxyribonucleotide.

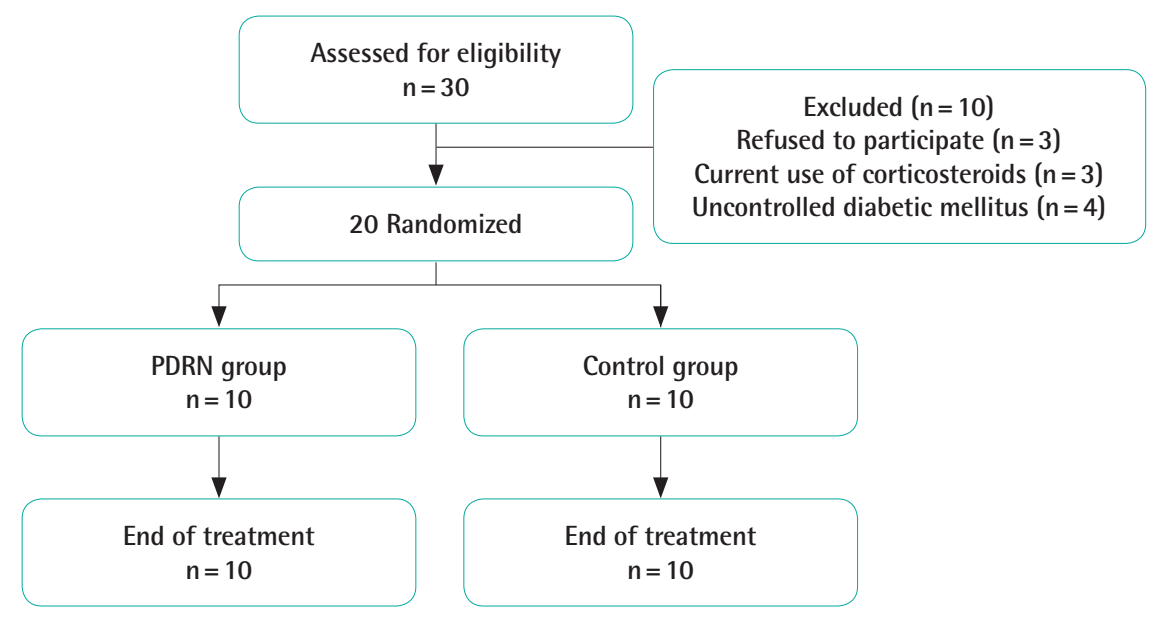

\section{Table 1. Baseline characteristics of the treatment and control groups}

\begin{tabular}{lcc}
\hline Characteristic & Control $(\boldsymbol{n}=10)$ & PDRN $(\mathbf{n}=10)$ \\
\hline Age $(\mathrm{yr})$ & $62 \pm 11.3(43-78)$ & $64 \pm 12.2(44-82)$ \\
Duration of wound before evaluation $(\mathrm{mo})$ & $1.2 \pm 0.8(0.3-3.0)$ & $1.1 \pm 0.72(0.2-2.5)$ \\
Wound size after initial debridement $\left(\mathrm{cm}^{2}\right)$ & $5.7 \pm 3.7(1.0-14.5)$ & $5.9 \pm 3.8(1.5-13.5)$ \\
Ankle-brachial index & $1.04 \pm 0.14(0.84-1.26)$ & $1.07 \pm 0.13(0.88-1.31)$
\end{tabular}

Values are presented as mean \pm standard deviation (range).

PDRN, polydeoxyribonucleotide.

All data were expressed as mean \pm standard deviation. All results were calculated with GraphPad Prism (ver. 5.02; GraphPad Software, La Jolla, CA, USA). P-values $<0.05$ were considered to indicate statistical significance.

\section{RESULTS}

Of the 30 patients who were screened, 10 were excluded: 3 refused to participate, 3 patients were excluded due to concurrent corticosteroid use, and 4 patients were excluded because of uncontrolled diabetes mellitus. A total of 20 patients were enrolled in the study: 10 in the control group and 10 in the PDRN group (Fig. 4).

In the control group, the mean age was $62 \pm 11.3$ years (range, 43-78 years) and the duration of the wound before evaluation was $1.2 \pm 0.8$ months (range, $0.3-3.0$ months). The wound size after initial debridement averaged $5.7 \pm 3.7 \mathrm{~cm}^{2}$ (range, 1.0-14.5 $\mathrm{cm}^{2}$ ) and the average ankle-brachial index was $1.04 \pm 0.14$ (range, 0.84-1.26). In the PDRN-treated group, the mean age was $64 \pm 12.2$ years (range, $44-82$ years) and the mean duration of the wound before medical treatment was $1.1 \pm 0.72$ months (range, 0.2-2.5 months). The wound size after initial debridement averaged $5.9 \pm 3.8 \mathrm{~cm}^{2}$ (range, $1.5-13.5 \mathrm{~cm}^{2}$ ), and the average ankle-brachial index was $1.07 \pm 0.13$ (range, $0.88-1.31$ ) (Table 1).

\section{PDRN increased peripheral tissue oxygenation}

The control group had relative $\mathrm{TcPO}_{2}$ values (the $\mathrm{TcPO}_{2}$ value on the measured day divided by the initial $\mathrm{TcPO}_{2}$ value) of 0.97 on day $1,0.99$ on day $3,1.01$ on day $7,1.00$ on day 14 , and 1.046 on day 28. The PDRN group had relative $\mathrm{TcPO}_{2}$ values of 0.97 on day $1,1.04$ on day $3,1.19$ on day $7,1.30$ on day 14 , and 1.30 on day 28. No statistically significant difference was observed between the groups on day $1(\mathrm{P}>0.05)$ and day $3(\mathrm{P}>0.05)$. Compared with the control group, the PDRN-treated group showed a statistically significant difference on day $7(\mathrm{P}<0.01)$, day $14(\mathrm{P}<0.001)$, and day $28(\mathrm{P}<0.001)$ (Fig. 5$)$.

\section{PDRN improved inflammation, increased granulation tissue formation, and increased angiogenesis}

In the histologic evaluation, inflammation in the PDRN group showed improvements compared to the control group. In the 


\section{Fig. 5. $\mathrm{TcPO}_{2}$ results}

No statistically significant difference was found on days 1 or 3 . The PDRN-treated group showed statistically significant differences on days 7, 14, and 28. All data are expressed as mean \pm standard deviation. Relative value (the $\mathrm{TCPO}_{2}$ value on the measured day divided by the initial $\mathrm{TcPO}_{2}$ value). PDRN, polydeoxyribonucleotide; $\mathrm{TcPO}_{2}$ transcutaneous oxygen tension. ${ }^{* *} \mathrm{P}<0.01 ;{ }^{* * *} \mathrm{P}<0.001$.

$\mathrm{TcPO}_{2}$

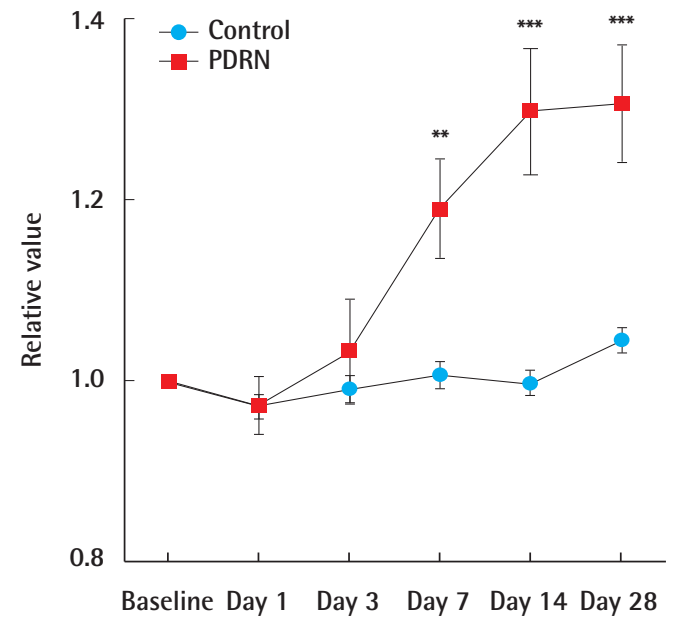

control group, acute and chronic inflammation persisted with neutrophil pigmentation. However, the PDRN-treated group exhibited less neutrophil pigmentation than the control group. The vessel density (average number of vessels per visual field) in the control group was $2.56 \pm 0.42$ (range, 1.9-3.1) before treatment and $2.78 \pm 0.47$ (range, 1.9-3.5) after 2 weeks of $0.9 \%$ normal saline injections. The vessel density in the PDRN group was $2.72 \pm 0.48$ (range, 2.1-3.7) before treatment and 3.28 \pm 0.87 (range, 2.0-4.6) after 2 weeks of PDRN injections. Compared to the control group, the PDRN-treated group showed increased granulation tissue formation with higher-density vascular markings (Figs. 6, 7). However, this relationship failed to reach statistical significance $(\mathrm{P}=0.094)$ (Fig. 8).

\section{DISCUSSION}

In this study, PDRN was successfully used to improve peripheral tissue oxygenation and angiogenesis. PDRN also improved inflammation.

Diabetic foot ulcers are difficult to deal with due to the com-

\section{Fig. 6. Histologic evaluation of the control group}

(A) Pre-treatment $\left(H \& E_{1} \times 40\right)$; necrosis with neutrophil pigmentation. (B) Post-treatment $\left(H \& E_{1} \times 40\right)$; persistent acute and chronic inflammation. (C) Pretreatment $\left(H \& E_{1} \times 200\right)$; inflammation with necrosis. (D) Post-treatment $\left(H \& E_{1} \times 200\right)$; vascular marking (yellow arrows) with granulation tissue formation.
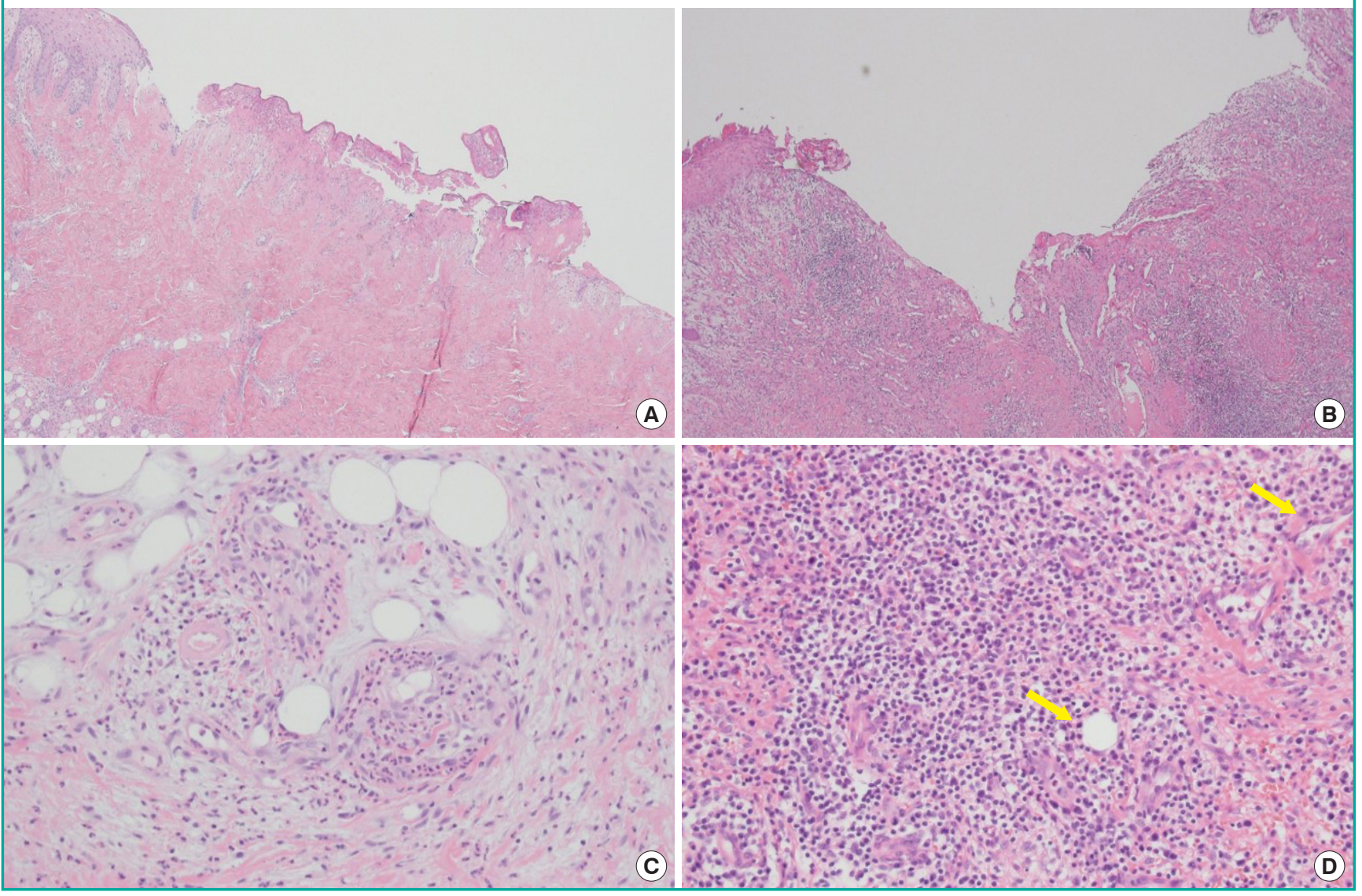


\section{Fig. 7. Histologic evaluation of the PDRN-treated group}

(A) Pre-treatment $\left(H \& E_{1} \times 40\right)$; central ulcer with necrosis, pigmented neutrophils (ellipse). (B) Post-treatment (H\&E, $\left.\times 40\right)$; inflammation improved. (C) Pre-treatment $\left(H \& E_{1} \times 200\right)$, (D) Post-treatment $\left(H \& E_{1} \times 200\right)$; vascular proliferation (yellow arrows) with granulation tissue formation. $H \& E_{1}$ hematoxylin and eosin; PDRN, polydeoxyribonucleotide.
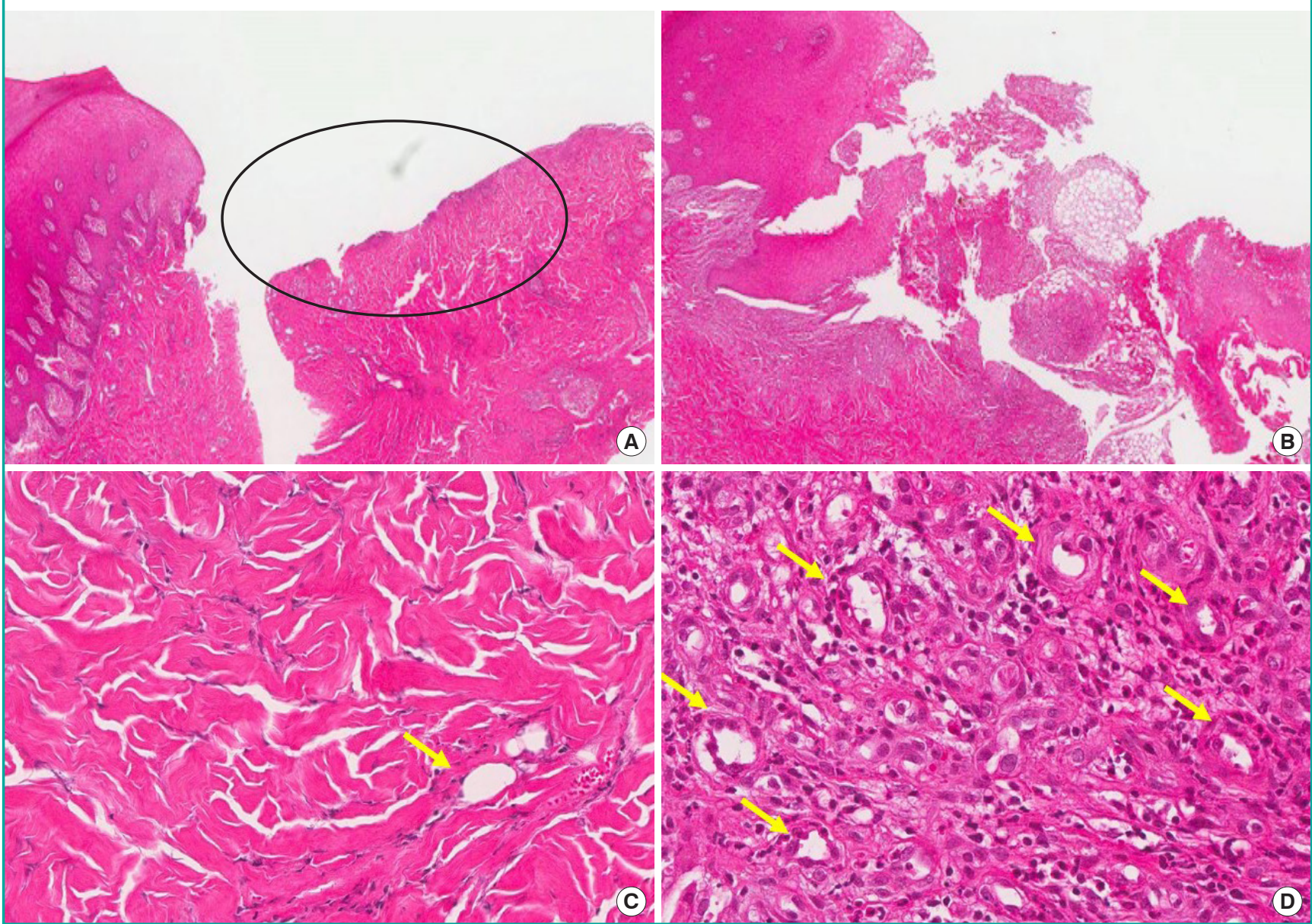

\section{Fig. 8. Vessel density}

No statistically significant difference was found between the control group and the PDRN group in vessel density (average number of vessels per visual field) $(P=0.094)$. All data are expressed as mean \pm standard deviation. PDRN, polydeoxyribonucleotide.

\section{Microvasculature}

Pre-treatment Post-treatment

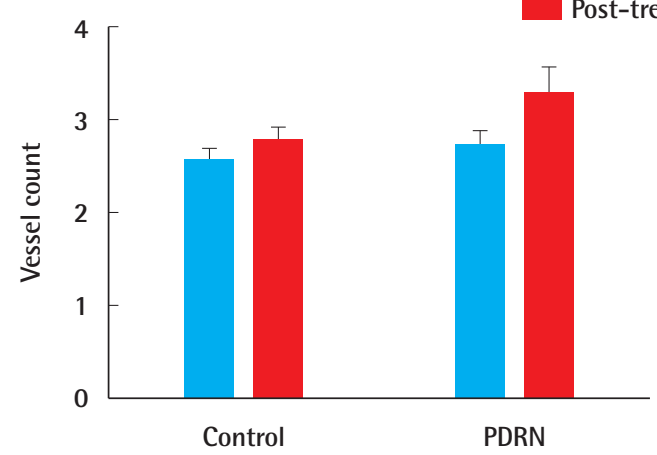

bined effects of peripheral neuropathy, peripheral vascular disease, and infection. Although diabetic foot ulcers are managed with various types of surgical procedures, there is no definitive therapeutic drug intervention that can accelerate the healing of diabetic foot ulcers. Considerable research into the effects of PDRN has been conducted in a diverse range of clinical fields. PDRN is the active fraction of a preparation used in therapy as a tissue repair and stimulating agent, and is extracted from the sperm of trout bred for human consumption [14]. In previous studies, PDRN accelerated wound healing in diabetic mice [5]. In other studies, PDRN improved blood flow in peripheral artery occlusive disease in rats [8]. In addition, PDRN stimulated corneal epithelium regeneration after photorefractive keratectomy [15]. A randomized, double-blind, placebo-controlled trial found that PDRN exerted favorable effects on the healing of chronic diabetic foot ulcers [11]. In previous studies, insufficient data were reported about the effects of PDRN on peripheral tissue oxygenation and about the pathologic features associ- 
ated with PDRN treatment, especially in diabetic foot ulcers. The authors monitored peripheral tissue oxygenation with the Periflux System 5000 (using the $\mathrm{TcPO}_{2} / \mathrm{CO}_{2}$ unit 5040) and observed that PDRN improved peripheral tissue oxygenation. In this study, peripheral tissue oxygenation $\left(\mathrm{TcPO}_{2}\right)$ in the PDRN-treated group was significantly higher on day $7(\mathrm{P}<$ $0.01)$, day $14(\mathrm{P}<0.001)$, and day $28(\mathrm{P}<0.001)$. Additionally, more vessel proliferation was found in the PDRN-treated group. Based on these results, PDRN seems to activate vascular proliferation, thereby increasing peripheral tissue oxygenation.

The angiogenesis cascade has not been fully elucidated due to its high degree of complexity. However, angiogenic factors such as vascular endothelial growth factor (VEGF) and transforming growth factor beta have been shown to increase angiogenesis effectively $[16,17]$. Extracellular adenosine actions are mediated by the activation of 4 distinct $G$ protein-coupled cell surface receptors $\left(A_{1}, A_{2 A}, A_{2 B}\right.$, and $\left.A_{3}\right)$ [18]. PDRN stimulates adenosine $A_{2 A}$ receptors under pathological conditions of low tissue perfusion [14]. PDRN exerts angiogenic effects via VEGF augmentation [8]. To assess the angiogenic effect of PDRN, we conducted a quantitative histologic assessment of the microvasculature. Although the PDRN treatment group demonstrated a mild increase in the vessel count, this trend was not statistically significant. Although we did not obtain significant results in the histologic analysis, the augmentation of tissue oxygenation was also an important result, with implications for angiogenesis. To clarify the exact effects of PDRN on diabetic foot ulcers, further experiments with a larger number of patients are necessary.

Our study had some limitations, such as an insufficient number of enrolled patients. Moreover, the short follow-up period was a limitation. Further, the absence of an immunohistochemical analysis in the present study prevented us from accurately evaluating wound regeneration on the molecular level. In the next phase of the study, immunohistochemical studies will be included in order to examine the effects of PDRN. Additionally, in the present study, changes in the wound surface area after PDRN injection were not evaluated. In another study, PDRN had favorable effects on the healing of diabetic foot ulcers with conservative dressing [11]. Although our study focused on the effects of PDRN in a treatment plan that included surgical management, an assessment of wound size alteration would have been desirable. Further studies are necessary.

In this study, we found that PDRN improved peripheral tissue oxygenation and angiogenesis. Additionally, PDRN had a positive effect on inflammation in diabetic foot ulcers. This study suggests that PDRN may be an effective and safe treatment option for diabetic foot ulcers, in addition to the standard treatments that are currently available.

\section{CONFLICT OF INTEREST}

No potential conflict of interest relevant to this article was reported.

\section{PATIENT CONSENT}

The patient provided written informed consent for the publication and the use of their images.

\section{REFERENCES}

1. Stadelmann WK, Digenis AG, Tobin GR. Impediments to wound healing. Am J Surg 1998;176(2A Suppl):39S-47S.

2. Simms M. Surgical treatment of the neuroischemic foot. J Cardiovasc Surg (Torino) 2009;50:293-311.

3. Guizzardi S, Galli C, Govoni P, et al. Polydeoxyribonucleotide (PDRN) promotes human osteoblast proliferation: a new proposal for bone tissue repair. Life Sci 2003;73:197383.

4. Sini P, Denti A, Cattarini G, et al. Effect of polydeoxyribonucleotides on human fibroblasts in primary culture. Cell Biochem Funct 1999;17:107-14.

5. Galeano M, Bitto A, Altavilla D, et al. Polydeoxyribonucleotide stimulates angiogenesis and wound healing in the genetically diabetic mouse. Wound Repair Regen 2008;16: 208-17.

6. Bitto A, Galeano M, Squadrito F, et al. Polydeoxyribonucleotide improves angiogenesis and wound healing in experimental thermal injury. Crit Care Med 2008;36:1594-602.

7. Polito F, Bitto A, Galeano M, et al. Polydeoxyribonucleotide restores blood flow in an experimental model of ischemic skin flaps. J Vasc Surg 2012;55:479-88.

8. Bitto A, Polito F, Altavilla D, et al. Polydeoxyribonucleotide (PDRN) restores blood flow in an experimental model of peripheral artery occlusive disease. J Vasc Surg 2008;48: 1292-300.

9. Brander VA, Gomberawalla A, Chambers M, et al. Efficacy and safety of hylan G-F 20 for symptomatic glenohumeral osteoarthritis: a prospective, pilot study. Pm r 2010;2:25967.

10. Kim JY, Pak CS. Effects of polydeoxyribonucleotide in the treatment of pressure ulcers. J Korean Med Sci 2014;29 Suppl 3:S222-7.

11. Squadrito F, Bitto A, Altavilla D, et al. The effect of PDRN, an adenosine receptor $\mathrm{A} 2 \mathrm{~A}$ agonist, on the healing of chronic diabetic foot ulcers: results of a clinical trial. J Clin Endocrinol Metab 2014;99:E746-53. 
12. Tellechea A, Kafanas A, Leal EC, et al. Increased skin inflammation and blood vessel density in human and experimental diabetes. Int J Low Extrem Wounds 2013;12:4-11.

13. Cheong H, Kang H, Kim HK, et al. Microvessel and lymphatic vessel density and VEGFR-3 expression of papillary thyroid carcinoma with comparative analysis of clinicopathological characteristics. Korean J Pathol 2010;44:243-51.

14. Altavilla D, Bitto A, Polito F, et al. Polydeoxyribonucleotide (PDRN): a safe approach to induce therapeutic angiogenesis in peripheral artery occlusive disease and in diabetic foot ulcers. Cardiovasc Hematol Agents Med Chem 2009; 7:31321.

15. Lazzarotto M, Tomasello EM, Caporossi A. Clinical evaluation of corneal epithelialization after photorefractive kera- tectomy in patients treated with polydeoxyribonucleotide (PDRN) eye drops: a randomized, double-blind, placebocontrolled trial. Eur J Ophthalmol 2004;14:284-9.

16. Montesinos MC, Desai A, Chen JF, et al. Adenosine promotes wound healing and mediates angiogenesis in response to tissue injury via occupancy of $\mathrm{A}(2 \mathrm{~A})$ receptors. Am J Pathol 2002;160:2009-18.

17. Gurunluoglu R, Meirer R, Shafighi M, et al. Gene therapy with adenovirus-mediated VEGF enhances skin flap prefabrication. Microsurgery 2005;25:433-41.

18. Hasko G, Linden J, Cronstein B, et al. Adenosine receptors: therapeutic aspects for inflammatory and immune diseases. Nat Rev Drug Discov 2008;7:759-70. 